\title{
Gelatina em pó e anilina como corantes para evidenciação da vascularização do fígado e adjacências de cadáveres de cães
}

\section{Powder gelatin and anilin dye as stains for the study liver and adjacent structures vascularization of dogs cadavers}

\author{
João Cesar Dias Oliveira, ${ }^{*}$ Alceu Gaspar Raiser, ${ }^{\star \star}$ Luiz Carlos de Pellegrini, ${ }^{* \star \star}$ Ricardo Alexandre Hippler ${ }^{\star \star \star \star}$
}

\begin{abstract}
Resumo
A visibilização e a identificação macroscópica dos vasos que irrigam os tecidos é facilitada quando forem utilizadas substâncias com poder corante ou de distensão vascular. Nesta pesquisa, foram comparadas as soluções de anilina hidrossolúvel para tecidos têxteis a $1 \%$, de gelatina em pó a $20 \%$, e uma mistura de ambas, na proporção de 1:1, para perfusão do sistema vascular de 30 cães, com ênfase para região do fígado e adjacências. Os resultados indicaram vantagens e desvantagens de cada corante isoladamente, sendo que a associação de ambos é a mais vantajosa.
\end{abstract}

Palavras-chave: anatomia; corante; cão.

\begin{abstract}
The visual observation and macroscopic identification of the vessels that irrigate the corporal tissues is greatly facilitated using special stainning dyes, or using vessel distenders. In a first stage, the water soluble anilin dye at a concentration of $1 \%$, and a commercially available gelatin powder at a concentration of $20 \%$, or a mixture of both, were used to perfuse the vascular system of the hepatic and adjacent region of 30 dogs. The analysis of the results indicated that the combination of gelatin/anilin gives better results than the use of each dye alone.
\end{abstract}

Keywords: anatomy; dye; collateral vascularization; viscera; dog.

\section{Introdução}

A visibilização macroscópica dos vasos que irrigam os órgãos é facilitada quando forem utilizadas substâncias que evidenciem determinadas estruturas num dado sítio anatômico. Para isso são empregados produtos que venham a aderir à camada interna ou que preencham a luz vascular.

Vários produtos têm sido utilizados para melhor identificar o suprimento sangüíneo a um determinado tecido. Entre os mais usados estão o acetato de vinil corado com posterior corrosão pelo ácido sulfúrico a $30 \%$ e o neoprene Látex 650 corado com pigmento específico, com subseqüente corrosão ou não (Rodrigues, 1973 ; Viana, 1986 ; Ashdown, Done, 1987 ; Santos et al., 1991 ; Evans, de Lahunta, 1994). Segundo Kraemer et al. (1988), esses produtos são importados e de difícil aquisição. Citam, ainda, que o látex exige consideráveis pressões para infundi-lo através da árvore vascular e que, em alguns casos, são relatadas retrações e preenchimento incompleto do sistema vascular. Em função do exposto, deve-se procurar meios alternativos de contraste vascular que sejam de baixo custo e fácil aquisição no país.
De acordo com Rodrigues (1973), existem vários produtos que podem ser usados para injeção em artérias e veias. Entre os recomendados estão a gelatina incolor em folhas dissolvida em água (12 folhas $/ 250 \mathrm{ml}$ ) em banho-maria de $40^{\circ} \mathrm{C}$ a $60^{\circ} \mathrm{C}$, com adição de corante vermelhão ou azul ultramarinho após a dissolução da gelatina. O cadáver a ser perfundido também deve ser aquecido em banho quente de $45^{\circ} \mathrm{C}$ a $55^{\circ} \mathrm{C}$ por duas horas.

A gelatina misturada com sulfato de bário foi utilizada por Buss et al. (1983) e Watanabe (1990), assim como em misturas com tinta nanquim por Andrade, Brito (1981) e Marinkovic, Gibo (1995) e com óxido de chumbo (PbO) por Rees, Taylor (1986) e Taylor, Minabe (1992) para identificação da vascularização de diferentes órgãos e tecidos. Kraemer et al. (1988) desenvolveram uma massa radiopaca para a repleção vascular utilizando bariogel, gelatina em pó e goma arábica, sendo necessário banho-maria a $45^{\circ} \mathrm{C}$ para homogeneização dos produtos e lavagem da árvore vascular com soro fisiológico a $40^{\circ} \mathrm{C}$. As substâncias para injeção ou repleção vascular, segundo Rodrigues (1973), podem ser líquidas ou solidificáveis, podendo ser coloridas com corantes como * Médico Veterinário, Professor Assistente, Departamento de Morfologia, Centro de Ciências da Saúde, Universidade Federal de Santa Maria
(UFSM), 97105-900 Santa Maria, RS. Autor para correspondência.

** Médico Veterinário, Professor Titular, Curso de Pós-Graduação em Medicina Veterinária, UFSM.

*** Médico Veterinário, Professor, Departamento de Clínica de Grandes Animais, UFSM.

${ }^{\star \star \star \star}$ Acadêmico do Curso de Medicina Veterinária (UFSM), Bolsista de Iniciação Científica do CNPq. 
sulfureto de mercúrio, cromato de chumbo e os corantes de anilina, entre outros. Gunn et al. (1986) avaliaram, através de estudo radiográfico, a presença ou ausência de irrigação sangüínea com acompanhamento da progressão e distribuição do meio de contraste radiopaco.

O estudo anatômico da vascularização nos órgãos é de significativa importância para a clínica e a cirurgia. Assim, foi objetivo da presente pesquisa avaliar o comportamento da gelatina em pó e/ou da anilina para tecidos, como corantes vasculares alternativos da vascularização hepática $e$ adjacências em cadáveres de cães.

\section{Material e métodos}

Foram utilizados 30 cães adultos, machos ou fêmeas, sem raça definida, provenientes da rotina clínico-cirúrgica do Hospital Veterinário (HV) da Universidade Federal de Santa Maria, encaminhados para eutanásia por causas variadas, mas que não interferissem com a integridade vascular ou hepática. Foram separados aleatoriamente em três grupos de igual número conforme recebessem, respectivamente, solução de gelatina (grupo 1), solução de anilina hidrossolúvel (grupo II) ou uma associação das duas substâncias (grupo III) para coloração vascular.

Os animais foram pré-medicados com maleato de acepromazina' $(0,02 \mathrm{mg} / \mathrm{kg})$, submetidos a tricotomia da região ventral do pescoço (Regio colli ventralis) (International Committee on Veterinary Gross Anatomical Nomenclature, 1994), e indução e anestesia com tiopental sódico² (30 mg/ $\mathrm{kg}$ ). Já na mesa cirúrgica receberam $7500 \mathrm{Ul}$ de heparina, ${ }^{3}$ via intravenosa. A seguir, foram posicionados em decúbito dorsal e o campo operatório foi submetido a anti-sepsia. Na seqüência, foi feita abordagem das artérias carótidas comuns ( $A$. carotis communis) e de uma das veias jugulares externas ( $V$. jugularis externa). Após dissecação, em cada vaso foram adaptados dois fios de reparo, sendo um para ligadura e outro para fixação do cateter ou cânula inserido em sua luz. Na veia jugular, foi feita incisão em $V$ com tesoura de Mayo ponta fina, para introdução da extremidade distal de um equipo para soro ${ }_{z}^{4}$ contendo solução de cloreto de sódio $0,9 \%$, cuja ponta foi conduzida até a junção das veias cavas ( $V$. cava). Á extremidade livre do equipo, foi conectada uma seringa com êmbolo pressionado temporariamente, a qual, após o início da perfusão, foi substituída por um frasco de drenagem. Na artéria carótida foi introduzido, de maneira semelhante, um cateter de equipo para soro ou um cateter de polietileno $n^{\circ} 120$ de acordo com a espessura do vaso, cuja ponta foi posicionada no tronco braquiocefálico (Truncus brachiocephalicus). A porção livre permaneceu clampeada temporariamente. A outra carótida foi cateterizada e conectada a um manômetro de mercúrio para monitoração da pressão arterial média.

Efetuada a cateterização dos vasos, o cateter da carótida foi conectado à cânula de uma bomba de roletes, ${ }^{5}$ que determinou perfusão vascular com o agente de contraste, sob pressão controlada (Figura 1).

\footnotetext{
' Acepran 0,2\%: Univet S:A:, São Paulo, SP.

2 Thionembutal: Abbott Laboratórios do Brasil Ltda., São Paulo, SP.

${ }_{3}$ Heparin: Cristália Produtos Químicos Farmacêuticos Ltda., Itapi, SP.

${ }_{4}$ Macro Gotas: Indústrias de Produtos Hospitalares Ltda., Curitiba, PR.

${ }^{5}$ Bomba de roletes De Backey: Oficinas do Hospital de Clínicas, São Paulo, SP.
}

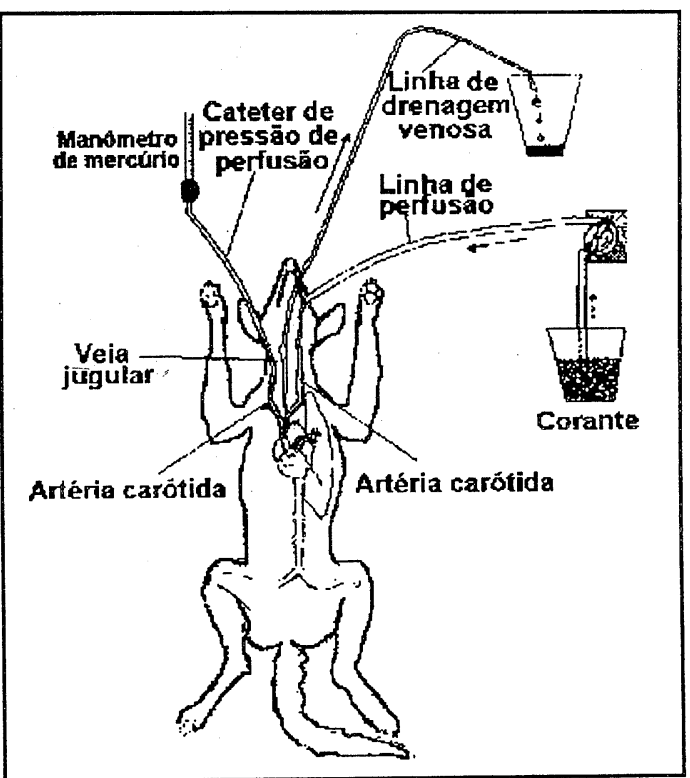

Figura 1: Esquema representativo do processo de exanguinação e perfusão com a solução corante para estudo de evidenciação vascular do fígado e adjacências em cão.

Como corantes foram utilizadas a gelatina ${ }^{6}$ em pó de cor verde (sabor limão) e a anilina ${ }^{7}$ hidrossolúvel para tingimento de tecidos têxteis nas cores verde ou azul, sendo a gelatina diluída a $20 \%$ e a anilina a $1 \%$, ambas em água morna $( \pm$ $40^{\circ} \mathrm{C}$ ). Quando misturadas, a proporção foi de 1:1. Preparados os corantes, uma das extremidades da cânula de perfusão foi conectada ao recipiente com o produto e a outra conectada ao cateter ou equipo da artéria carótida comum (Figura 1). 0 corante foi perfundido a uma velocidade de $\pm 30 \mathrm{rpm}$ com uma pressão arterial de $110 \mathrm{mmHg}$. Após o início da perfusão, a seringa do cateter de drenagem na veia jugular foi removida, permitindo que se processasse a drenagem do sangue. $O$ animal foi perfundido por tempo suficiente para que o produto drenado tivesse coloração semelhante àquele introduzido no cateter da carótida. Logo após o início da perfusão, os animais foram sacrificados pelo aprofundamento da anestesia.

Durante a perfusão foram anotados os volumes de perfusão e exanguinação e a velocidade de perfusão, além do grau de repleção e coloração dos vasos periféricos.

Concluída a perfusão, foram removidos os cateteres dos vasos, seguindo-se ligadura dos mesmos e reconstituição do plano cirúrgico abordado. Os cães perfundidos com gelatina pura ou em associação foram encaminhados para câmara fria visando a geleificação do corante. Os cães perfundidos com gelatina foram necropsiados (Barros, 1988) após 48 horas, e os perfundidos somente com anilina, ao término do procedimento. A artéria aorta ( $A$. aorta) foi ligada e seccionada no arco (Arcus aortae) e caudal à origem das artérias renais (A. renalis); a veia cava caudal ( $V$. cava caudalis), logo cranial ao diafragma ( $M$. diaphagma), no tórax (Thorax), e após a

\footnotetext{
${ }^{6}$ Gelatina Royal: Produtos Alimentícios Fleischmann e Royal Ltda., Rio de Janeiro, RJ.

7 AG Anilinas Gaúcha: CCE Indústria e Comércio de Anilinas, Porto Alegre, RS.
} 
junção das veias renais ( $V$. renalis). Foram também ligadas e seccionadas as artérias gástricas ( $A$. gastrica), esplênicas ( $A$. lienalis), veia porta ( $V$. portae) e ducto colédoco (Ductus choledocus). À necropsia observou-se, também, o preenchimento vascular e a impregnação dos tecidos adjacentes. A coluna vertebral (Columna vertebralis) foi seccionada no quinto espaço intercostal (Spatium intercostale) e caudal ao ponto de ligadura da artéria aorta. O bloco, então, contendo fígado (Hepar), diafragma e adjacências, foi removido e fixado em formalina ${ }^{8}$ a $10 \%$ por, no mínimo, 24 horas, com posterior dissecação, observando-se o grau de impregnação e distensão dos vasos e a capacidade de penetração do contraste nos pequenos vasos.

\section{Resultados e discussão}

Os vasos preenchidos pela solução de anilina a $1 \%$ não apresentaram distensão vascular, mas uma excelente impregnação pelo corante, mesmo aqueles de diâmetro reduzido, o que é explicado pelo seu alto poder de aderência, à semelhança do que se observa no tingimento de tecidos têxteis. Nos vasos perfundidos com solução de gelatina a $20 \%$, sem adição de corante, a coloração não foi muito evidente, enquanto que a distensão vascular sim, pois em sua fórmula não existem componentes com grande poder de aderência, somente para geleificação. Esta constatação concorda com Buss et al. (1983), Kraemer et al. (1988) e Watanabe (1990), que utilizaram gelatina misturada com sulfato de bário, bem como com Andrade, Brito (1981) e Marinkovic, Gibo (1995), os quais usaram solução de gelatina com tinta nanquim. Já Rees, Taylor (1986) e Taylor, Minabe (1992) fizeram uso do óxido de chumbo (PbO) adicionado à gelatina para identificação da irrigação de determinadas áreas anatômicas. Como se observa, a gelatina pode ser associada a diferentes corantes, obtendo-se, assim, um duplo efeito, a coloração e o preenchimento vascular. Nos cães perfundidos com a mistura anilina/gelatina, o sistema vascular apresentou distensão vascular e impregnação pelo corante, evidenciando mesmo os vasos de pequeno calibre. No presente experimento, a associação foi a que apresentou o meIhor resultado, concordando com os dados obtidos por Rodrigues (1973) após a utilização dos corantes de anilina para coloração de substâncias para repleção vascular.

O volume injetado variou de 64 a $283 \mathrm{ml} / \mathrm{kg}$ para anilina, $112 \mathrm{e}$ $500 \mathrm{ml} / \mathrm{kg}$ para a gelatina e de 91 a $250 \mathrm{ml} / \mathrm{kg}$ para a associação anilina-gelatina. Os tempos de perfusão ficaram entre 2,4 e 15 minutos com uso da anilina, 4,1 a 25 minutos com a gelatina e entre 3,1 e 15 minutos na associação das duas. Os volumes e tempos relativamente baixos com a utilização da solução de anilina foram devidos ao seu alto grau de dissolução com o sangue, o que foi comprovado pela rápida mudança de coloração das mucosas, do tecido subcutâneo e do líquido drenando pela jugular. A solução de gelatina, ao contrário, não apresentou uma boa visibilização, requerendo tempo e volume de perfusão maiores. Nos animais perfundidos com a mistura gelatina/anilina foram reduzidos o volume e o tempo de perfusão.

As variações nos tempos de injeção também estão relacionados ao diâmetro do dispositivo usado. A tentativa de canular a carótida dos animais de pequeno porte com o equipo para

\footnotetext{
${ }^{8}$ Formol Líquido 40\%: Importadora Química Delaware Ltda., Porto Alegre, RS
}

soro foi infrutífera, optando-se, então, pelo cateter de polietileno de diâmetro menor. Taylor, Minabe (1992) fizeram observações semelhantes, quando citaram que o tempo de perfusão está relacionado com a espessura do cateter, sendo maior em animais de pequeno porte. No atual experimento, manteve-se a taxa de perfusão em nível constante de 30rpm. Com isso, o uso de cateter de menor diâmetro resultou em demanda de mais tempo para a perfusão.

A perfusão vascular, segundo Rees, Taylor (1986), deve ser feita de maneira pulsátil (pressão e retração) simulando o pulso arterial, com uso de seringa de $50 \mathrm{ml}$, para evitar a ruptura de pequenos vasos. Em função dessa recomendação, optou-se pela perfusão utilizando a bomba de roletes de Backey, a qual injeta o corante com movimentos pulsáteis e tem a vantagem de manter constantes a freqüência e intensidade de pulso. Mesmo assim, houve impregnação em algumas áreas adjacentes à vascularização, quando foi utilizada a solução de anilina (Figura 2), dificultando a visibilização dos vasos, o que não ocorreu com o uso da solução de gelatina a $20 \%$ e da mistura gelatina/anilina (Figura 3). Não foi possível determinar se esse extravasamento foi devido à ruptura de vasos de pequeno calibre, especialmente veias, ou se pela difusão através da parede vascular.

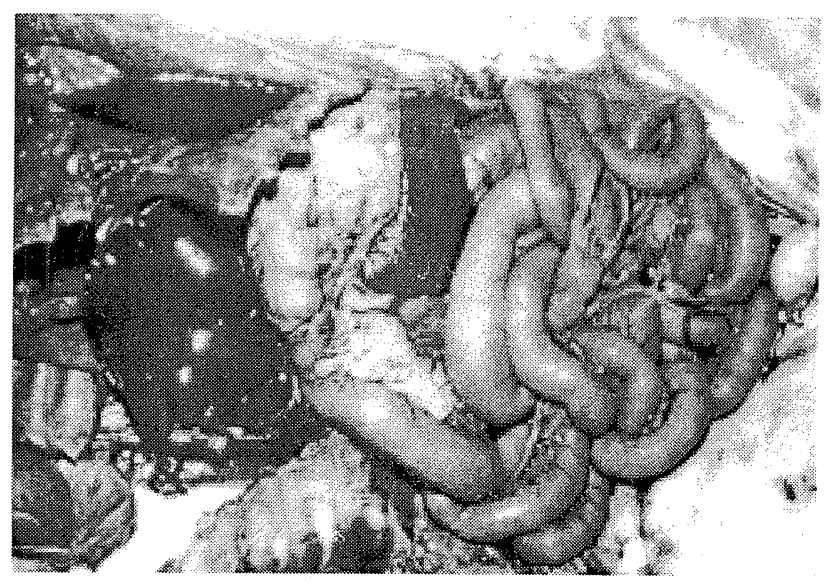

Figura 2: Aspecto da impregnação das vísceras abdominais de um cão, após a perfusão com solução de anilina, para estudos de visibilização vascular.

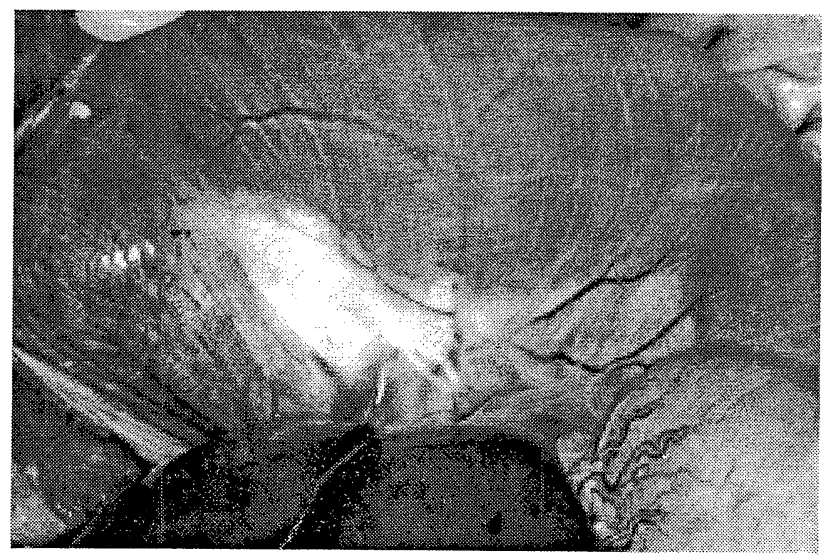

Figura 3: Apresentação vascular após a perfusão com solução da mistura gelatina/anilina em cão. Visualiza-se o diafragma no plano maior, fígado no plano inferior esquerdo e estômago no plano inferior direito. 


\section{Conclusões}

Em função dos resultados obtidos, conclui-se que:

A anilina hidrossolúvel para tecidos permite evidenciação vascular, porém impregna tecidos adjacentes, dificultando a identificação de pequenos vasos; a solução de gelatina em

\section{Referências bibliográficas}

ANDRADE, Z.A., BRITO, P.A. Evolution of schistosomal hepatic vascular lesions after specific chemotherapy. Am J Trop Med Hyg, Baltimore, v. 30, n. 6, p. 1223-1227, 1981.

ASHDOWN, R.R., DONE, S. Atlas colorido de anatomia veterinária. São Paulo : Manole, 1987.234 p.

BARROS, C.S.L. Guia da técnica de necropsia dos mamíferos domésticos. Santa Maria : Imprensa Universitária, 1988. 47 p.

BUSS, D.D., HYDE, D.M., STEFFEY, E.P. Coronary collateral development in the rhesus monkey (Macaca mulatta). Basic Res Cardiol, Darmstadt, v. 78, n. 5, p. 510-517. 1983.

EVANS, H.E., DE LAHUNTA, A. Miller guia para a dissecação do cão. 3. ed. Rio de Janeiro: Guanabara Koogan, 1994. 206 p.

GUNN, C., GOURLEY, I.M., KOBLIK, P.D. Hepatic dearterialization in the dog. Am J Vet Res, Chicago, v. 47, n. 1, p. 170-175, 1986.

INTERNATIONALCOMMITTEEON VETERINARYGROSSANATOMICAL NOMENCLATURE. Nomina anatomica veterinaria. 4. ed. Ithaca : World Association of Veterinary Anatomists, 1994. 348 p.

KRAEMER, J.L., SCHNEIDER, F.L., SEVERINO, A.G. et al. Massa radiopaca para repleção vascular. Rev bras Ciên morfol, São PauIo, v. 5, n. 2, p. 122-124, 1988. pó oferece adequado preenchimento vascular, pela considerável distensão devido à geleificação, porém proporciona pobre visibilização; a mistura da gelatina/anilina é mais vantajosa, pela associação do efeito corante da anilina com o poder distensor da gelatina, proporcionando evidenciação por coloração e distensão vascular.

MARINKOVIC, S.V., GIBO, $H$. The blood supply of the trigeminal nerve root, with special reference to the trigeminocerebellar artery. Neurosurgery, Baltimore, v. 37, n. 2, p. 309-317, 1995.

REES, M.J.W., TAYLOR, G.I. A simplified lead oxide cadaver injection techenic. Plast Reconstr Surg, Baltimore, v. 77, n. 1, p. 141-145, 1986.

RODRIGUES, H. Técnicas anatômicas. Juiz de Fora : Imprensa Universitária, 1973. 218 p. Cap. 3: angiotécnicas: p. 75-114.

SANTOS, R.M.B., PRADA, I.L.S., DIDIO, L.J.A. Hepatic veins and liver segmentation in ovine (Ovis aries). Braz J Vet Res Anim Sci, São Paulo, v. 28, n. 1, p. 19-30, 1991.

TAYLOR, G.I., MINABE, T. The angiosomes of the mammals and other vertebrates. Plast Reconstr Surg, Baltimore, v. 89, n. 2, p. 181-215, 1992.

VIANA, W.G. Contribuição ao estudo do funículo espermático em bovinos da raça Nelore, 1986. 59 p. Tese (Anatomia) Instituto de Ciências Biomédicas da USP. Universidade de São Paulo.

WATANABE, L.M. Efeitos da vagotomia gástrica proximal sobre a vascularização arterial da curvatura menor do estômago, 1990. 92 p. Tese (Ćlínica Cirúrgica) - Faculdade de Medicina de Ribeirão Preto. Universidade de São Paulo.

\section{E T U S \\ NIKON (Japão) \\ Distribuidor Nacional}

Cetus Hospitalar Comércio e Representações Ltda. Microscópios Biológicos e Industriais - Espectofotômetros -
Deonizadores - Kits para bioquímica - Contador de Células

\section{Assistência Técnica}

Rua Lopes Trovão, 75 - Benfica

20920-310 - Rio de Janeiro - RJ

Tel.: (21) 568-9345

Fax: (21) 264-3628

E-mail: cetus@abeunet.com.br 